\title{
PEMANFAATAN KOLEKSI REPOSITORY PERPUSTAKAAN FAKULTAS MIPA UGM MENGGUNAKAN EPRINTS
}

\author{
Wiyarsih*
}

\begin{abstract}
This study aims to identify the utilization of repository collection at FMIPA UGM library using Eprints. It is a descriptive study with a quantitative approach. The subjects were librarians utilizing repository collection. The object was repository collection. Methods of data collection in this study were observation, documentation, and questionnaires. Data were analyzed quantitatively. The result of the study showed that the librarian managed to meet the target of uploading as many as 3100 documents in PDF file within 1 month (July 2014) but the proportion based on department was yet as expected. Average utilization of repository collections at FMIPA UGM library was 70.45\%. This was considered as very good. The highest score of satisfaction was found in the quality of repository collection (87.75\%) and the lowest was in the number of documents used (35.4\%). Respondents used repository collection within 1-2 hours per day (80.0\%). Respondents read and took notes (80.0\%). As many as $87.75 \%$ of respondents considered that repository collection of FMIPA library was of good quality, particularly viewed from aspects of currency and relevance to user needs.
\end{abstract}

Keywords: Utilization; repository; E-prints

* Pustakawan UGM dpk Perpustakaan FMIPA UGM

\section{A. PENDAHULUAN}

\section{Latar Belakang}

Perkembangan teknologi yang pesat telah mempengaruhi berbagai segi kehidupan manusia.Perpustakaan sebagai salah satu institusi pengelola informasi juga dipengaruhi oleh perkembangan teknologi terutama teknologi informasi (TI). Adanya perkembangan TI, koleksi perpustakaan dalam wujud cetak dapat dialihmediakan menjadi format digital. Kelebihan koleksi dalam format digital antara lain dapat diakses secara cepat dan mudah, dapat digunakan secara bersama-sama dari mana saja dan kapan saja, serta menghemat tempat penyimpanan.

Perpustakaan FMIPA UGM sebagai bagian dari perpustakaan perguruan tinggi juga telah memanfaatkan TIuntuk mengelola koleksi perpustakaan. Perpustakaan FMIPA UGM mempunyai 9.780 koleksi digital yang terdiri dari skripsi, tugas akhir, laporan kerja praktek, tesis dan disertasi. Pertumbuhan dan perkembangan koleksi digital tersebut sangat pesat sehingga perlu dikelola dengan baik agar dapat diakses dengan mudah dan pemanfaatannya dapat berkelanjutan. Koleksi lokal digital tersebut merupakan koleksi repository. Menurut Daniel Pandapotan H. (2013), repository adalah konsep untuk mengumpulkan, mengelola, menyebarkan dan mengelola seluruh karya-karya ilmiah yang di hasilkan oleh civitas perguruan tinggi.
Karya-karya tersebut akan difungsikan dan dikelola dalam bentuk digital serta dapat menjadi pendukung dalam proses pemenuhan informasi baik institusi atau masyarakat umum.

Koleksi repository Perpustakaan FMIPA UGM belum dikelola secara sistematis, yakni hanya disimpan dalam hard disk, sehingga ada hambatan baik dalam pengelolaan maupun proses temu kembali. Di sisi lain, di era digital ini pemustaka membutuhkan layanan yang mudah, cepat dan akurat. Untuk itu diperlukan suatu aplikasi untuk mengelola koleksi repository sehingga lebih mudah diakses oleh pemustaka. Menurut Al. Pramukti Narendra (2014), dewasa ini ada banyak ditawarkan berbagai perangkat lunak untuk mengelola dokumen karya ilmiah dan gratis. Nama software itu antara lain: Dispace, Green Stone, GDL, dan Eprints.

Eprints merupakan perangkat lunak perpustakaan digital yang dikembangkan oleh University of Southampton, England United Kingdom.Versi pertama Eprints di-release ke publik pada tahun 2000.Eprints sudah terintegrasi dengan extended metadata, advanced search untuk penelusuran informasi lanjut, dan fitur-fitur lainnya. Eprints merupakan perangkat lunak perpustakaan berbasis opensource, sehingga dapat dimodifikasi dan disesuaikan dengan kebutuhan lokal (http://eprints.org). Selain itu 
perangkat lunak Eprints terbanyak penggunanya kedua setelah Dspace (http://dspace.org) (Fuad, 2013).

Melihat bebcrapa kelebihan software Eprints di atas maka Perpustakaan FMIPA UGM akan menerapkan Eprints untuk mengelola koleksi digital. Dengan menggunakan Eprints, diharapkan dapat meningkatkan pemanfaatan koleksi repository oleh mahasiswa sehingga dapat mendukung tugas mereka dalam membuat karya ilmiah. Penelitian ini dilakukan untuk mengetahui bagaimana pemanfaatan koleksi repository di Perpustakaan Fakultas MIPAUGM menggunakan Eprints".

\section{Rumusan Masalah}

a. Seberapa besar koleksi repository yang diunggah ke dalam software Eprints oleh petugas perpustakaan berdasarkan proporsional jurusan?

b. Bagaimana pola pemanfaatan koleksi repository Perpustakaan Fakutlas MIPA UGM menggunakan Eprints oleh pemustaka?

c. Bagaimana kepuasan pemustaka terhadap pemanfaatan koleksi repository Perpustakaan Fakultas MIPA UGM menggunakan Eprints oleh pemustaka?

\section{Tujuan}

a. Mengetahui besarnya koleksi repository Perpustakaan Fakultas MIPA UGM yang diunggah petugas perpustakaan berdasarkan proporsional jurusan.

b. Mengetahui pola pemanfaatan koleksi repository Perpustakaaan FMIPA UGM menggunakan Eprints oleh pemustaka.

c. Mengetahui kepuasan pemustaka terhadap pemanfaatan koleksi repository Fakultas MIPAUGM mengggunakan Eprints.

\section{Manfaat}

a. Dapat mengumpulkan koleksi repository dalam satu tempat penyimpanan

b. Dapat melestarikan koleksi repository

c. Dapat mendayagunakan koleksi repository

d. Koleksi repository dapat diakses dengan mudah

e. Meningkatkan jumlah pemustaka yang memanfaatkan koleksi repository

f. Memperlancar mahasiswa dalam menyelesaikan karya ilmiah g. Bagi pengambil kebijakan, agar dapat menambah sarana prasarana layanan repository.

\section{B. TINJAUAN PUSTAKA}

\section{Perpustakaan Perguruan Tinggi}

Menurut Undang-Undang Perpustakaan Nomor 43 Tahun 2007, perpustakaan adalah institusi pengelola koleksi karya tulis, karya cetak, dan/atau karya rekam secara profesional dengan sistem yang baku guna memenuhi kebutuhan pendidikan, penelitian, pelestarian, informasi, dan rekreasi para pemustaka. Sedangkan perpustakaan perguruan tinggi (PT) menurut Qolyubi dkk (2003), merupakan unit pelaksana teknis (UPT) perguruan tinggi yang bersama-sama dengan unit lain turut melaksanakan Tri Dharma Perguruan Tinggi dengan cara memilih, menghimpun, mengolah, merawat dan melayankan sumber informasi kepada lembaga induknya pada khususnya dan masyarakat akademis pada umunya.

Dalam Undang-Undang Nomor 43 Tahun 2007 menyebutkan bahwa perpustakaan perguruan tinggi memiliki koleksi, baik jumlah judul maupun jumlah eksemplarnya, yang mencukupi untuk mendukung pelaksanaan pendidikan, penelitian, dan pengabdian kepada masyarakat. Selanjutnya disebutkan bahwa perpustakaan perguruan tinggi mengembangkan layanan perpustakaan berbasis teknologi dan komunikasi.

Menurut Sulistyo-Basuki (1993) secara umum tujuan perpustakaan perguruan tinggi adalah:

a. Memenuhi keperluan informasi masyarakat perguruan tinggi, lazimnya staf pengajar dan mahasiswa. Seing pula mencakup pula tenaga administrasi perguruan tinggi.

b. Menyediakan bahan pustaka rujukan (referensi) pada semua tingkat akademis, artinya mulai dari mahasiswa tahun pertama hingga ke mahasiswa program pasca sarjana dan pengajar.

c. Menyediakan ruangan belajar untuk pemakai perpustakaan.

d. Menyediakan jasa peminjaman yang tepat guna bagia berbagai jenis pemakai.

e. Menyediakan jasa informasi aktif yang tidak saja terbatas pada lingkungan perguruan tinggi tetapi juga lembaga industri lokal. 


\section{Pemanfaatan Perpustakaan}

Menurut Badudu, (1994), pemanfaatan berasal dari kata dasar manfaat yang berarti guna, faedah, sedangkan memanfaatkan berarti membuat sesuatu menjadi berguna, maka pemanfaatan adalah hal, cara, hasil kerja memanfaatkan.

King dan Palmour yang dikutip oleh Pudji Mulyono (1995) dalam Yuli Rohmiyati (2006) menyatakan bahwa pemanfaatan perpustakaan dapat ditinjau dari dua sisi yaitu cara pengunjung perpustakaan menggunakan informasi dan efek dari penggunaan informasi.

Untuk mengetahui sejauh mana pemanfaatan jasa perpustakaan, menurut Lasa Hs (2005:318), dapat dilihat dari beberapa unsur, antara lain:

1. Pertanyaan referensi yang dijawab secara benar, penelusuran literatur yang terpenuhi maupun jasa bibliografi yang lengkap.

2. Rasio pemakai sesungguhnya dengan pemakai potensial.

3. Rasio pelayanan tertentu seperti online service, konsultasi dan lainnya dengan jumlah pemakai.

4. Rasio semua pengguna pelayanan dengan seluruh pelayanan yang disajikan.

5. Jumlah koleksi yang dimanfaatkan selama 24 jam.

6. Rasio seluruh koleksi dengan seluruh pemanfaatan.

7. Rasio koleksi yang disirkulasikan dengan jumlah pemakai yang aktif.

8. Rasio antara koleksi yang disirkulasikan dengan berbagai kelompok pemakai.

9. Pemanfaatan jasa perpustakaan secara keseluruhan.

10. Persentasi antara pemanfaatan jenis koleksi dengan kelompok pemakai seperti peneliti, dosen, siswa, pejabat pemerintah dan lainnya.

\section{Koleksi Perpustakaan}

Undang-Undang Nomor 43 Tahun 2007 menyebutkan bahwa koleksi perpustakaan adalah semua informasi dalam bentuk karya tulis, karya cetak, dan/atau karya rekam dalam berbagai media yang mempunyai nilai pendidikan, yang dihimpun, diolah, dan dilayankan.

Melihat dari wadah dan penciptaannya, koleksi terdiri dari: 1). Bahan tercetak (printed), seperti: buku, majalah, surat kabar, tesis, skripsi, selebaran dan lain sebagainya yang dicetak berbasis kertas; 2). Bahan terekam (recorded), seperti: kaset, video, disket, CD-ROOM, bahan pandang dengar (audio visual), kit, realia, multimedia, dan lain sebagainya yang direkam dalam berbagai media misalnya di atas pitamagnetik; 3). Bahan terpasang (online), di mana secara fisik tidak ada di perpustakaan, tetapi dapat diakses melalui jaringan teknologi informasi. E-book, e-journals adalah eontoh koleksi terpasang (Rachman Hermawan dan Zulfikar Zen, 2006)

Menurut Sutarno (2005:100), koleksi atau sumber informasi perpustakaan merupakan salah satu pilar atau kekuatan dan daya tarik utama bagi pengunjung. Oleh sebab itu agar pilar tersebut kuat maka koleksi perpustakaan juga harus kuat, dalam pengertian memadai dalam jumlah, jenis, ragam dan mutu.

\section{Institutional Repository}

Menurut Pendit (2008), istilah Institutional Repository atau "Simpanan Kelembagaan" merujuk ke sebuah kegiatan menghimpun dan melestarikan koleksi digital yang merupakan hasil karya intelektual dari sebuah komunitas tertentu.

Mustaine (2008) dalam Siagian (2009), menjelaskan bahwa:

The word repository can refer to a central place where data can be stored or maintained, the term Repository can also refer to a certain place which is specifically used to store digital data, it can refer to a site wher a-prints are situated. Repository also means a place where many multiple databases or files are located which is later used for distribution over a specific network. It can also refer to a computer location which is directly accessible to user without him searching or logging on to the entire network. In short repository means a place where anything is stored which can later be used again.

Berdasarkan pendapat di atas dapat diketahui bahwa repository berarti suatu tempat untuk menyimpan dan melestrarikan informasi digital yang didistribusikan dalam jaringan komputer untuk digunakan kembali.

Repository dapat berarti gudang sehingga bisa mencakup perpustakaan, museum, arsip bahkan juga gudang.Kini pengertian institutional repository (selanjutnya disingkat IR) mengacu pada penyimpanan dan preservasi informasi digital sebuah organisasi atau aset pengetahuan sebuah organisasi (Branin, 2010, dalam Alb. Pramukti Narendra, 2014)

Mark \& Shearer (2006) dalam Alb. Pramukti Narendra(2014) menyatakan bahwa "an 
Institutional Repository is a way for every academic institution so 'showcase' its intellectual prowess through the systematic collection, organization, making accessible and preservation of its intellectualoutput."

Definisi dari University of Houston (2006) dalam Alb. Pramukti Narendra (2014) bahwa repositori institusi didefinisikan sebagai " $a$ permanent, institute-wide repository of diverse locally produced digital neworks (e.g. article preprints and postprints, data sets, electronic theses and dissertations, learning objects, and technical reports that is available for public use and supports metadataharvesting"

Raym Crow (2002) dalam Muh Ahlis Ahwan (2012) menyebutkan bahwa jenis koleksi yang disediakan pada sebuah Institutional Repository dapat berupa proposal penelitian, hasil penelitian, buku lepas, bahan pengajaran, buku, data, laporan penelitian, prosiding atau hasil seminar, skripsi, tesis, disertasi, dan buku panduan.

Karakteristik koleksi institutional repository menurut Pendit (2008) adalah:

a. Pengirim materi untuk disimpan bukanlah hanya si pembuat, tetapi juga pemilik karya (misalnya penerbit yang sudah membeli hak cipta dari penulis) dan pihak ketiga (misalnya pustakawan).

b. Selain karya, disimpan pula metadata dari karya tersebut, dan ini dimungkinkan karena perangkat lunaknya memang sudah dilengkapi dengan boring untuk mengisi metadata secara mudah.

c. Pada umumnya tersedia mekanisme sederhana untuk meletakkan, mengambil mencari dokumen.

d. Karena mengendalikan inisiatif dari pihak pengirim, maka sebuah simpanan kelembagaan perlu mendapatkan kepercayaan dan dukungan.

e. Karakteristik sctiap simpanan kelembagaan terntu saja sangat ditentukan oleh lembaga tempatnya berada, selain oleh jenis koleksinya, yang terutama merupakan hasil penelitiannya.

Freedom Foundation USA (2007) dalam Siagian (2009), menyatakan bahwa repository adalah:

A repository is a place where data or speciments are stored and maintained for future retrieval. Repositorycan be:

- Aplace where data are stored

- A place where specifically digital data are stored
- A site where eprints are located

- A place where multiple databases or files are located for distribution over a network

- A computer location that is directly accessible to the user without having to travel across a network

- $\quad$ A place to store speciments, including serum or other biological fractions

- A place where anyting is stored for probable reuse.

Menurut Pandapotan H.(2013), ada 4 hal yang menjadi perhatian utama bagi eksistensi institutional repository sebuah perguruan tinggi, diantaranya sebagai berikut:

1. Untuk mengumpulkan konten dalam satu lokasi sehingga mudah untuk ditemukan kembali.

2. Untuk menyimpan dan melestarikan aset intelektual sepanjang waktu.

3. Untuk menyediakan akses terbuka terhadap karya intelektual institusi kepada khalayak umum.

4. Untuk menciptakan visibilitas global bagi hasil karya ilmiah institusi.

Berdasarkan beberapa pendapat di atas dapat disimpulkan bahwa perpustakaan perguruan tinggi sebagai pendukung tri dharma perguruan tinggi, mempunyai tugas mengelola koleksi untuk memenuhi kebutuhan pemustaka. Salah satu jenis koleksi di perpustakaan perguruan tinggi adalah koleksi karya ilmiah mahasiswa seperti skripsi, tesis dan disertasi yang merupakan koleksi lokal baik dalam bentuk tercetak maupun digital. Koleksi lokal tersebut perlu dikelola menggunakan sarana teknologi agar mudah diakses dan dimanfaatkan oleh pemustaka. Koleksi lokal dalam bentuk digital dari suatu institusi yang dikelola dan disimpan dalam suatu tempat serta didistribusikan melalui jaringan komputer agar dapat digunakan lagi oleh masyarakat institusi maupun masyarakat umum disebut sebagai Institutional Repository (IR). Salah satu software untuk mengelola koleksi repository adalah Eprints. Dengan adanya IR diharapkan koleksi repository dapat diakses dengan mudah dari mana saja dan kapan saja.

\section{METODE PENELITIAN}

Penelitian ini merupakan penelitian deskriptif dengan pendekatan kuantitatif. 
Penelitian dilakukan di Perpustakaan Fakultas MIPA UGM selama 6 bulan, yaitu bulan Juni sampai dengan November 2014.

Subjek penelitian ini adalah pemustaka yang memanfaatkan repository Perpustakaan FMIPA UGM. Sedangkan objeknya adalahpemanfaatan koleksi repository Perpustakaan FMIPA UGM menggunakan Eprints.

Dalam penelitian ini variabelnya adalah pola pemanfaatan dan kepuasan pemustaka terhadap pemanfaatan koleksi repository Perpustakaan FMIPA UGM. Indikator variabel pola pemanfaatan koleksi repository meliputi: frekuensi pemanfaatan, intensitas pemanfaatan, jumlah dokumen yang dimanfaatkan, titik akses dalam melakukan penelusuran dokumen, perlakuan terhadap hasil penelusuran dokumen yang ditemukan dan bentuk koleksi yang sering dimanfaatkan.

Indikator variabel kepuasan pemustaka terhadap koleksi repository meliputi: kualitas koleksi repository, kuantitas koleksi repository, kemudahan akses, kualitas software Eprints, kuantitas hardware komputer, dan hasil pemanfaatan koleksi repository.

Populasinya ada 2 (dua) jenis, yaitu seluruh pemustaka yang memanfaatkan layanan repository FMIPA UGM dan seluruh koleksi digital repository FMIPA UGM. Dalam penelitian ini juga ada 2 (dua) macam sampel, yaitu pemustaka (mahasiswa) yang memanfaatkan layanan repository dan koleksi repository FMIPA UGM. Pengambilan sampel untuk pemustaka dengan menggunakan teknik penarikan sampel aksidental (aksidental sampling) Dalam penelitian ini, sampel untuk pemustaka dihitung dari jumlah pemustaka yang kebetulan memanfaatkan repository selama 1 (satu) bulan, yaitu pada bulan September 2014.
Sampel dari koleksi repository diambil menggunakan proportionate stratified random sampling. Menurut Sugiyono (2005) teknik ini digunakan bila populasi mempunyai anggota/unsur yang tidak homogen dan berstrata secara proporsional. Jumlah koleksi repository yang dimiliki Perpustakaan FMIPA adalah 9.780judul yang terdiri dari 6 (enam) subjek bidang ilmu yaitu matematika, fisika, kimia, komputer, elektronika dan instrumentasi (elins) dan rekam medis (rekmed).

Dalam penelitian ini jumlah sampel ditetapkan 30\% dari jumlah keseluruhan, yaitu sebesar 2.934 judul. Jumlah koleksi masingmasing subjek ilmu adalah: fisika 1.090, matematika 2.553, kimia 839, komputer 3.266, elektronika dan instrumentasi 1.584, dan koleksi rekam medis 448, sehingga jumlah sampel masing-masing subjek adalah:

$$
\begin{array}{ll}
\text { Fisika } & =\frac{1090 \times 2934}{9780}=327 \\
\text { Matematika } & =\frac{2553}{9780} \times 2934=766 \\
\text { Kimia } & =\frac{839 \times 2934}{9780}=252 \\
\text { Komputer } & =\frac{3266}{9780} \times 2934=980 \\
\text { Elins } & =\frac{1584}{9780} \times 2934=475 \\
\text { Rekmed } & =\frac{448}{9780} \times 2934=134
\end{array}
$$

Dalam penelitian ini peneliti menggunakan instrumen angket atau kuesioner. Berikut adalah tabel kisi-kisi angketnya:

Tabel 1. Kisi-kisi angket

\begin{tabular}{llcc}
\hline \multicolumn{1}{c}{ Variabel } & \multicolumn{1}{c}{ Indikator } & No. Item Jumlah \\
\hline Pola pemanfaatan & 1. Frekuensi pemanfaatan & 1 & 1 \\
\hline koleksi repository & 2. Intensitas pemanfaatan & 2 & 1 \\
\hline & 3. Jumlah dokumen yang dimanfaatkan & 3 & 1 \\
\hline & 4. Titik akses melakukan penelusuran dokumen & 4 & 1 \\
\hline & 5. Perlakuan terhadap dokumen yang diperoleh & 5 & 1 \\
\hline & 6. Bentuk dokumen yang sering dimanfaatkan & 6 & 1 \\
\hline Kepuasan pemustaka & 1. Kualitas koleksi repository & $7-8$ & 2 \\
\hline & 2. Kuantitas koleksi repository & 9 & 1 \\
\hline & 3. Kemudahan akses & $10-11$ & 2 \\
\hline 4. Kualitas software Eprints & 12 & 1 \\
\hline 5. Kuantitas hardware komputer & 13 & 1 \\
\hline 6. Hasil pemanfaatan & $14-15$ & 2 \\
\hline
\end{tabular}

Sumber: Data primer diolah September 2014 
Pada penelitian ini instrumen yang diuji validitasnya adalah instrumen pemanfaatan koleksi repository Perpustakaan Fakultas MIPA UGM. Pengujian validitas dilakukan dengan menghitung korelasi antara masing-masing pertanyaan dengan skor total dengan menggunakan teknik korelasi product moment, yang dilakukan dengan bantuan komputer menggunakan program SPSS versi 15 for windows.

Rumus korelasi yang digunakan adalah rumus korelasi product moment yang dikemukakan oleh Pearson (Arikunto, 2002):

$$
r_{x y} \frac{N \sum X Y-\left(\sum X\right)\left(\sum Y\right)}{\sqrt{\left\{N \sum X^{2}-\left(\sum X\right)^{2}\right\}\left\{N \sum X Y^{2}-\left(\sum Y\right)^{2}\right\}}}
$$

Keterangan:

$\mathrm{r}_{\mathrm{xy}}=$ Koefisien korelasi antara skor butir dengan skor total

$\mathrm{N}=$ Jumlah subyek uji coba

$\sum \mathrm{X}=$ Jumlah skor butir (X)

$\sum \mathrm{X}^{2}=$ Jumlahskor butir kuadrat $(\mathrm{X})$

$\sum \mathrm{Y}=$ Jumlah skor total $(\mathrm{Y})$

$\sum \mathrm{Y}^{2}=$ Jumlah skor total kuadrat $(\mathrm{Y})$

$\mathrm{XY}=$ Jumlah perkalian skor butir dengan skor total

Untuk mencari reliabilitas instrumen pada penelitian ini menggunakan rumus Alpha. Menurut Arikunto (2002), rumus Alpha digunakan untuk mencari reliabilitas instrumen yang skornya bukan 1 dan 0 , misalnya angket atau soal bentuk uraian. Rumus Alpha tersebut adalah:

$$
r_{11}=\left[\frac{k}{k-1}\right]\left[1-\frac{\sum \sigma_{b}^{2}}{\sigma_{1}^{2}}\right]
$$

Keterangan:

$\mathrm{r}_{11}=$ reliabilitas instrumen

$\mathrm{k}$ = banyaknsa butir pertanyan atau banyaknya nol

$\sum \sigma_{b}^{2}=$ jumlih varians bulir

$\sigma_{1}^{2} \quad \cdots$ rarians lota!
Metode pengumpulan data yang digunakan dalam penelitian ini adalah:

a. Metode observasi

Observasi dilakukan di bagian layanan repository FMIPA UGM dengan maksud agar mendapatkan gambaran yang utuh tentang objek yang diteliti.

b. Metode dokumentasi

Dokumen yang akan diperiksa adalah daftar pemanfaatan layanan repository yang diisi oleh pemustaka.

c. Metode kuesioner

Model penelitian yang akan digunakan adalah kuesioner tertutup. Menurut Arikunto (1993), kuesioner tertutupadalah kuesioner yang sudah disediakan jawabannya sehingga responden tinggal memilih.

Analisis data dilakukan setelah data dari seluruh responden atau sumber data lainterkumpul.Analisis data yang digunakan adalah analisis deskriptif.

Beberapa tahap analisis data menurut Prasetyo dan Jannah (2005) adalah:

a. Pengkodean data (Data Coding)

Data coding merupakan suatu proses penyusunan secara sistematis data mentah (yang ada dalam kuesioner) ke dalam bentuk yang mudah dibaca oleh mesin pengolah data seperti komputer.

b. Pemindahan data ke komputer (Data Entering)

Data entering adalah memindahkan data yang telah diubah menjadi kode ke dalam mesin pengolah data.

c. Pembersihan Data (Data Cleaning)

Data cleaning adalah memastikan bahwa seluruh data yang telah dimasukkan ke dalam mesin pengolah data sudah sesuai dengan yang sebenarnya.

d. Penyajian data (Data ouput)

Data output adalah hasil pengolahan data.

Untuk menghitung persentase jawaban yang diberikan oleh responden digunakan rumus dari Hadi (1981) sebagai berikut: 


$$
\mathrm{P}=\frac{\mathrm{F}}{\mathrm{N}} \times 100 \%
$$

Keterangan:

$\mathrm{P}=$ Persentase

$\mathrm{F}=$ Frekuensi jawaban yang diperoleh

$\mathrm{N}=$ Jumlah responden

Prosentase jumlah jawaban responden dihitung dan dikelompokkan ke dalam penafsiran. Metode penafsiran menurut Supardi (1979) adalah sebagai berikut:

$1-25 \%$ : Sebagian kecil

$26-49 \%$ : Hampir setengah

$50 \%$ : Setengah

$51-75 \%$ : Sebagian besar

$76-99 \%$ : Pada umumnya

$100 \%$ : Seluruhnya

Untuk mengukur pemanfaatan koleksi repository Perpustakaan FMIPA UGM menggunakan Eprints, menggunakan penafsiran data dengan kriteria persentase dari Ridwan dan Adkon (2006:18) sebagai berikut:

$$
\begin{array}{ll}
1-25 \% & : \text { Sangat tidak baik } \\
26-50 \% & : \text { Tidak baik } \\
51-75 \% & : \text { Baik } \\
76-100 & : \text { Sangat baik }
\end{array}
$$

\section{HASIL DAN PEMBAHASAN}

\section{Uji Validitas Instrumen}

Instrumen pada penelitian ini terdiri dari dua bagian, bagian pertama yaitu pola pemanfaatan koleksi repository, sedangkan bagian kedua adalah kepuasan pemustaka. Instrumen pola pemanfaatan koleksi repository terdiri dari 6 butir pertanyaan, sedangkan instrument kepuasan pemustaka terdiri dari 9 butir pertanyaan dan totalnya adalah 15 butir pertanyaan. Adapun alat bantu pengolahan menggunakan program SPSS version 15 for windows.

a. ji Validitas Variabel Pola Pemanfaatan Koleksi Repository

Pengujian validitas dilakukan dengan menghitung korelasi antara masing-masing pertanyaan dengan skor total dengan menggunakan teknik korelasi product moment. Berdasarkan hasil pengujian validitas pola pemanfaatan koleksi repository tersebut, 6 butir pertanyaan dinyatakan valid atau shahih karena korelasi antara skor butir dengan skor total (r) dalam instrument lebih dari 0,3.
Menurut Sugiyono (1998: 148), syarat minimum yang dianggap memenuhi syarat/validitas adalah apabila $\mathrm{r}=0,3$. Berikut adalah tabel hasil uji validitas variabel pola pemanfaatan koleksi repository.

Tabel 2. Hasil Uji Validitas

\begin{tabular}{cc}
\hline Butir soal & r hitung \\
\hline 1 & 0,553 \\
\hline 2 & 0,456 \\
\hline 3 & 0,529 \\
\hline 4 & 0,428 \\
\hline 5 & 0,388 \\
\hline 6 & 0,408 \\
\hline
\end{tabular}

Sumber: Data primer diolah September 2014

\section{b. Uji Validitas Variabel Kepuasan Pemustaka}

Berdasarkan hasil pengujian validitas kepuasan pemustaka tersebut, 9 butir pertanyaan dinyatakan valid atau shahih karena korelasi antara skor butir dengan skor total (r) dalam instrument lebih dari 0,3. Berikut adalah tabel hasil uji validitas variabel validitas kepuasan pemustaka.

Tabel 3.Hasil Uji Validitas

\begin{tabular}{cc}
\hline Butir soal & r hitung \\
\hline 7 & 0,345 \\
\hline 8 & 0,510 \\
\hline 9 & 0,409 \\
\hline 10 & 0,624 \\
\hline 11 & 0,448 \\
\hline 12 & 0,603 \\
\hline 13 & 0,421 \\
\hline 14 & 0,425 \\
\hline 15 & 0,346 \\
\hline Sumber: Data primer diolah September 2014
\end{tabular}

2. Uji Reliabilitas Instrumen

Uji reliabilitas pola pemanfaatan koleksi repository dan kepuasan pemustaka dihitung dengan menggunakan koefisien Alpha.

a. Uji Reliabilitas Variabel Pola Pemanfaatan

\section{Koleksi Repository}

Berdasarkan hasil pengujian reliabitas pola pemanfaatan koleksi repository tersebut, 6 butir pertanyaan dinyatakan realibel karena $r$ lebih dari 0,60. Menurut Sugiono (1998: 149), apabila besarnya nilai $r$ antara 0,60-0,799 maka keandalannya termasuk kuat. Berikut adalah tabel hasil uji reliabilitas variabel pola pemanfaatan koleksi repository 
Tabel 4.

Hasil Uji Reliabilitas Pola Pemanfaatan Koleksi Repository

\begin{tabular}{cc}
\hline Butir soal & r hitung \\
\hline 1 & 0,646 \\
\hline 2 & 0,685 \\
\hline 3 & 0,651 \\
\hline 4 & 0,684 \\
\hline 5 & 0,694 \\
\hline 6 & 0,690 \\
\hline
\end{tabular}

Sumber: Data primer diolah September 2014

b. Uji Reliabilitas Variabel Kepuasan Pemustaka

Berdasarkan hasil pengujian reliabitas kepuasan pemustaka, 9 butir pertanyaan dinyatakan realibel karena $r$ lebih dari 0,60 . Berikut adalah tabel hasil uji reliabilitas variabel kepuasan pemustaka.
Tabel 5. Hasil Uji Reliabilitas

Kepuasan Pemustaka

\begin{tabular}{cc}
\hline Butir soal & r hitung \\
\hline 7 & 0,766 \\
\hline 8 & 0,741 \\
\hline 9 & 0,757 \\
\hline 10 & 0,720 \\
\hline 11 & 0,750 \\
\hline 12 & 0,725 \\
\hline 13 & 0,756 \\
\hline 14 & 0,756 \\
\hline 15 & 0,767 \\
\hline
\end{tabular}

Sumber: Data primer diolah September 2014

\section{Analisis Data}

Jumlah perolehan menurut proporsional subyek ilmu dibandingkan dengan target awal adalah sebagai berikut:

Tabel 6. Koleksi repository yang diunggah ke dalam software Eprints oleh petugas perpustakaan

\begin{tabular}{lcccc}
\hline Subyek & Target & Perolehan & Kelebihan & Kekurangan \\
\hline Fisika & 327 & 420 & 93 & - \\
\hline Matematika & 766 & 767 & 1 & - \\
\hline Kimia & 252 & 447 & 195 & - \\
\hline Komputer & 980 & 867 & - & 113 \\
\hline Elins & 475 & 407 & - & 68 \\
\hline Rekam Medis & 134 & 192 & 58 & - \\
\hline Jumlah & 2934 & 3100 & 347 & 181
\end{tabular}

Sumber: Data primer diolah September 2014

Berdasarkan tabel 6 dapat diketahui bahwa koleksi repository yang berhasil diunggah ke dalam software Eprints oleh petugas perpustakaan selama 1 bulan (Juli 2014) adalah sebesar 3.100 dokumen (judul). Apabila dilihat dari segi jumlah sudah mencapai target semula yaitu sebesar 2.934 judul.

Untuk analisis data pemanfaatan koleksi repository diperoleh dengan cara menyebarkan kuesioner kepada responden yang sedang mengakses koleksi repository. Data yang diperoleh dianalisis dengan metode deskriptif kuantitatif.

\section{a. Pola Pemanfaatan Koleksi Repository}

1. Frekuensi pemanfaatan koleksi repository

Frekuensi pemanfaatan koleksi repository dihitung dari frekuensi pemanfaatan koleksi repository perminggu.Berdasarkan datadikeahui bahwa sebagian kecil $(10,8 \%)$ responden memanfaatkan koleksi repository 5-6 kali per minggu, dan hampir setengah responden $(44,6 \%)$ memanfaatkan koleksi repository 1-2 kali per minggu. $\mathrm{Hal}$ ini terjadi karena koleksi repository yang sudah masuk ke dalam software Eprints baru $30 \%$. Di samping itu juga masih tersedia koleksi dalam bentuk cetak, sehingga ada alternatif lain dalam memanfaatkan koleksi.

b. Intensitas pemanfaatan koleksi repository

Intensitas pemanfaatan koleksi repository dihitung dari lama waktu dalam mengakses koleksi repository dalam satu hari. Berdasarkan datadiketahui bahwa sebagian kecil $(1,5 \%)$ responden memanfaatkan koleksi repository lebih dari 6 jam dan 5-6 jam. Pada umumnya $(80,0) \%$ ) responden memanfaatkan koleksi repository 1-2 jam sehari. Hal ini karena sebagian besar repsonden masih kuliah sehingga hanya mempunyai waktu 1-2 jam di sela-sela kuliah. Di samping itu membaca koleksi repository di depan layar komputer akan lebih cepat lelah dari pada melalui koleksi tercetak walaupun lebih mudah diakses.

c. Jumlah koleksi yang dimanfaatkan

Jumlah koleksi repository yang dimanfaatkan oleh pemustaka dihitung dari jumlah koleksi yang diakses per hari. Berdasarkan datadiketahui bahwa sebagian kecil $(10,8 \%)$ responden mengakses koleksi lebih dari 6 koleksi dalam sehari, dan hampir setengah $(35,4 \%)$ dari responden mengakses koleksi repository 1-2 koleksi per hari. Hal ini karena koleksi 
Tabel 4.

Hasil Uji Reliabilitas Pola Pemanfaatan Koleksi Repository

\begin{tabular}{cc}
\hline Butir soal & r hitung \\
\hline 1 & 0,646 \\
\hline 2 & 0,685 \\
\hline 3 & 0,651 \\
\hline 4 & 0,684 \\
\hline 5 & 0,694 \\
\hline 6 & 0,690 \\
\hline
\end{tabular}

Sumber: Data primer diolah September 2014

b. Uji Reliabilitas Variabel Kepuasan Pemustaka

Berdasarkan hasil pengujian reliabitas kepuasan pemustaka, 9 butir pertanyaan dinyatakan realibel karena r lebih dari 0,60 . Berikut adalah tabel hasil uji reliabilitas variabel kepuasan pemustaka.
Tabel 5. Hasil Uji Reliabilitas

Kepuasan Pemustaka

\begin{tabular}{cc}
\hline Butir soal & r hitung \\
\hline 7 & 0,766 \\
\hline 8 & 0,741 \\
\hline 9 & 0,757 \\
\hline 10 & 0,720 \\
\hline 11 & 0,750 \\
\hline 12 & 0,725 \\
\hline 13 & 0,756 \\
\hline 14 & 0,756 \\
\hline 15 & 0,767 \\
\hline
\end{tabular}

Sumber: Data primer diolah September 2014

\section{Analisis Data}

Jumlah perolehan menurut proporsional subyek ilmu dibandingkan dengan target awal adalah sebagai berikut:

Tabel 6. Koleksi repository yang diunggah ke dalam software Eprints oleh petugas perpustakaan

\begin{tabular}{lcccc}
\hline Subyek & Target & Perolehan & Kelebihan & Kekurangan \\
\hline Fisika & 327 & 420 & 93 & - \\
\hline Matematika & 766 & 767 & 1 & - \\
\hline Kimia & 252 & 447 & 195 & - \\
\hline Komputer & 980 & 867 & - & 113 \\
\hline Elins & 475 & 407 & - & 68 \\
\hline Rekam Medis & 134 & 192 & 58 & - \\
\hline Jumlah & 2934 & 3100 & 347 & 181 \\
\hline
\end{tabular}

Sumber: Data primer diolah September 2014

Berdasarkan tabel 6 dapat diketahui bahwa koleksi repository yang berhasil diunggah ke dalam software Eprints oleh petugas perpustakaan selama 1 bulan (Juli 2014) adalah sebesar 3.100 dokumen (judul). Apabila dilihat dari segi jumlah sudah mencapai target semula yaitu sebesar 2.934 judul.

Untuk analisis data pemanfaatan koleksi repository diperoleh dengan cara menyebarkan kuesioner kepada responden yang sedang mengakses koleksi repository. Data yang diperoleh dianalisis dengan metode deskriptif kuantitatif.

\section{a. Pola Pemanfaatan Koleksi Repository}

1. Frekuensi pemanfaatan koleksi repository

Frekuensi pemanfaatan koleksi repository dihitung dari frekuensi pemanfaatan koleksi repository perminggu.Berdasarkan datadikeahui bahwa sebagian kecil $(10,8 \%)$ responden memanfaatkan koleksi repository 5-6 kali per minggu, dan hampir setengah responden $(44,6 \%)$ memanfaatkan koleksi repository 1-2 kali per minggu. Hal ini terjadi karena koleksi repository yang sudah masuk ke dalam software Eprints baru 30\%. Di samping itu juga masih tersedia koleksi dalam bentuk cetak, sehingga ada alternatif lain dalam memanfaatkan koleksi.

b. Intensitas pemanfaatan koleksi repository

Intensitas pemanfaatan koleksi repository dihitung dari lama waktu dalam mengakses koleksi repository dalam satu hari. Berdasarkan datadiketahui bahwa sebagian kecil $(1,5 \%)$ responden memanfaatkan koleksi repository lebih dari 6 jam dan 5-6 jam. Pada umumnya $(80,0) \%$ ) responden memanfaatkan koleksi repository 1-2 jam sehari. Hal ini karena sebagian besar repsonden masih kuliah sehingga hanya mempunyai waktu 1-2 jam di sela-sela kuliah. Di samping itu membaca koleksi repository di depan layar komputer akan lebih cepat lelah dari pada melalui koleksi tercetak walaupun lebih mudah diakses.

c. Jumlah koleksi yang dimanfaatkan

Jumlah koleksi repository yang dimanfaatkan oleh pemustaka dihitung dari jumlah koleksi yang diakses per hari. Berdasarkan datadiketahui bahwa sebagian kecil $(10,8 \%)$ responden mengakses koleksi lebih dari 6 koleksi dalam sehari, dan hampir setengah $(35,4 \%)$ dari responden mengakses koleksi repository $1-2$ koleksi per hari. Hal ini karena koleksi 
tersebut diakses (dibaca atau dicatat) secara fullteks sehingga untuk mengakses koleksi 1-2 saja memerlukan waktu yang relatif lama. Untuk sebagian kecil responden yang mengakses koleksi lebih dari 6 koleksi, karena mereka hanya mengakses tidak secara fullteks tetapi hanya bagian-bagian dari dokumen, misalnya abstraknya saja.

d. Titik akses dalam melakukan penelusuran dokumen

Titik akses dalam melakukan penelusuran dokumen dihitung dari titik akses apayang digunakan responden dalam melakukan penelusuran dokumen. Berdasarkan data diketahui bahwa sebagian besar $(67,7 \%)$ responden melakukan penelusuran melalui judul dan tidak ada $(0 \%)$ responden yang melakukan penelusuran melalui pengarang tambahan. Sebagian besar responden melakukan penelusuran melalui titik akses judul karena akan lebih tepat dan cepat ditemukan karena judul hanya ada 1 macam. Responden tidak melakukan penelusuran melalui pengarang tambahan dalam hal ini adalah dosen pembimbing, karena kurang efektif dan tidak langsung mengenai sasaran dokumen yang dicari.

e. Perlakuan terhadap hasil penelusuran dokumen

Perlakuan terhadap hasil penelusuran dokumen dihitung dari perlakukan yang dilakukan terhadap dokumen yang telah diperoleh.Berdasarkan datadiketahui bahwa sebagian kecil responden $(1,5 \%)$ mencatat dokumen hasil penelusuran, dan pada umumnya $(80,0 \%)$ responden membaca dan mencatat dokumen hasil penelusuran. Dengan membaca dan mencatat, responden akan dapat mengetahui dan memilih bagian-bagian yang penting dari dokumen.

\section{f. Bentuk dokumen yang sering diakses}

Bentuk dokumen yang diakses dihitung dari pendapat responden tentang bentuk dokumen yang sering diakses. Berdasarkan data diketahui bahwa sebagian besar $(66,2 \%)$ responden mengakses abstrak dan fullteks, dan sebagian kecil $(3,1 \%)$ responden mengakses judulnya saja.Responden tidak hanya menginginkan judulnya saja, setelah ditemukan judul yang sesuai dengan yang dikehendaki maka responden akan mengakses abstrak dan fullteks-nya.

\section{g. Kualitas koleksi repository}

1. Kemutakhiran koleksi

Kemutakhiran koleksi dihitung dari tingkat kemutakhiran koleksi repository menurut responden. Berdasarkan data diketahui bahwa $93,8 \%$ responden berpendapat bahwa koleksi repository up to date, dan tidak ada $(0 \%)$ responden yang berpendapat bahwa koleksi repository out of date ataupun sangat out of date. Hal ini karena koleksi repository yang dimasukkan adalah koleksi 5 tahun terakhir, yaitu koleksi tahun 2010 sampai 2014.
2. Kesesuaian dokumen yang diperoleh dengan kebutuhan

Kesesuaian dokumen yang diperoleh dengan kebutuhan responden dihitung dari tingkat kesesuaian dokumen dengan kebutuhan responden. Berdasarkan data diketahui bahwa pada umumnya $(81,5 \%)$ responden menyatakan dokumen yang diperoleh sesuai dengan kebutuhan, dan tidak ada $(0 \%)$ responden yang menyatakan dokumen tidak sesuai dengan kebutuhan. Hal ini karena koleksi repository yang di up load ke software Eprints meliputi semua subjek ilmu sesuai jurusan yang ada di FMIPA, sehingga dapat memadai kebutuhan responden walaupun belum lengkap.

h. Kuantitas koleksi repository

Kuantitas koleksi repository dihitung dari pendapat responden tentang kuantitas koleksi repository. Berdasarkan data diketahui bahwa sebagian besar $(75,4 \%)$ responden menyatakan koleksi repository memadai, dan tidak ada $(0 \%)$ responden menyatakan koleksi repository tidak memadai.Hal ini karena sebagian besar responden mencari koleksi repository yang up to date, sehingga koleksi 5 tahun terakhir sudah dapat memadai bagi responden.

\section{i. Kemudahan akses}

1. Prosedur penelusuran koleksi repository

Prosedur penelusuran koleksi repository dihitung dari tingkat kemudahan prosedur penelusuran koleksi repository. Berdasarkan data diketahui bahwa sebagian besar $(72,3 \%)$ responden menyatakan prosedur penelusuran koleksi repository mudah, dan tidak ada $(0 \%)$ resonden menyatakan sangat tidak mudah. Hal ini karena software Eprints telah meyediakan fasilitas penelusuran melalui berbagai jalan dan dengan prosedur yang mudah dalam penelusuran koleksi baik melalui judul, subjek, tahun, dan pengarang.

\section{Kemudahan akses koleksi repository}

Kemudahan akses koleksi repository dihitung dari tingkat kemudahan akses koleksi repository. Berdasarkan data diketahui bahwa $81,5 \%$ responden menyatakan koleksi repository mudah ditemukan, dan tidak ada $(0 \%)$ responden yang menyatakan sangat tidak mudah ditemukan.Hal ini karena software Eprints sudah memberi kemudahan dalam mengakses koleksi, baik abstrak maupun fullteks.

j. Kualitas software Eprints

Kualitas software Eprints dihitung dari jumlah pendapat responden tentang kualitas software Eprints. Berdasarkan data diketahui bahwa pada umumnya $(76,9 \%)$ responden menyatakan kualitas software Eprints memadai, dan tidak ada $(0 \%)$ responden 
menyatakaan tidak memadai.Hal ini karena adanya kemudahan dalam prosedur penelusuran maupun dalam menemukan dokumen. Eprints mempunyai beberapa kelebihan, antara lain sudah terintegrasi dengan extended metadata, advanced search untuk penelusuran informasi lanjut, dan fitur-fitur lainnya.

k. Kuantitas Hardware Komputer

Kuantitas hardware komputer dihitung dari jumlah pendapat responden tentang kuantitas hardware komputer yang digunakan untuk akses koleksi repository. Berdasarkan data diketahui bahwa sebagian besar $(73,8 \%)$ responden berpendapat bahwa kuantitas hardware komputer memadai, dan tidak ada $(0 \%)$ responden yang menyatakan kuantitas hardware komputer tidak memadai. Walaupun jumlah komputer untuk akses koleksi repository baru berjumlah 4 unit, tetapi sudah memadai karena sebagian besar responden hanya mengakses selama 1-2 jam sehingga dapat bergantian, di samping itu juga masih tersedia koleksi tercetak.

1. Hasil pemanfaatan koleksi repository

1. Tingkat pemanfaatan koleksi repository

Hasil pemanfaatan koleksi repository dihitung dari tingkat pemanfaatan koleksi repository yang sudah diakses. Berdasarkan data diketahui90,8\% responden memanfaatkan koleksi repository yang sudah diakses dengan baik, dan tidak ada $(0 \%)$ responden memanfaatkan koleksi repository yang sudah diakses dengan sangat tidak baik. Koleksi repository yang sudah diakses merupakan bahan yang sangat penting sebagai referensi dalam pembuatan karya ilmiah, sehingga pada umumnya responden memanfaatkannya dengan baik.

2. Tingkat kepentingan koleksi repository yang diakses

Tingkat kepentingan koleksi repository yang diakses dihitung dari seberapa penting koleksi repository yang telah diakses oleh responden. Berdasarkan data diketahui bahwa sebagian besar $(70,8 \%)$ responden menyatakan koleksi repository membantu memenuhi ide bagi penyelesaian tugas akhir, tidak ada $(0 \%)$ responden yang berpendapat bahwa koleksi repository tidak membantu karena informasi yang dicari tidak tersedia. Berdasarkan hasil tersebut dapat diketahui bahwa koleksi repository sangat penting bagi sebagian besar $(70,8 \%)$ responden dalam memenuhi ide bagi penyelesaian tugas akhir, karena dengan membaca berbagai hasil penelitian yang sudah ada maka responden akan kaya dengan ide untuk menyelesaikan tugas akhir.

Berdasarkan keseluruhan analisis data, maka persentase dari hasil yang diperoleh dalam penelitian pemanfaatan koleksi repository Perpustakaan Fakultas MIPA UGM menggunakan Eprints dapat dilihat pada tabel 7 berikut ini:

Tabel 7. Data Pemanfaatan Koleksi Repository Perpustakaan Fakultas MIPA UGM Menggunakan Eprints

\begin{tabular}{|c|c|c|c|c|}
\hline Variabel & Indikator & Persentase & Persentase & Total Nilai \\
\hline & & & Rata-rata & Rata-rata \\
\hline A. Pola pemanfaatan & 1. Frekuensi pemanfaatan & 1. $44,6 \%$ & $44,6 \%$ & \\
\hline & 2. Intensitas pemanfaatan & 2. $80,0 \%$ & $80,0 \%$ & \\
\hline & $\begin{array}{l}\text { 3. Jumlah dokumen yang } \\
\text { dimanfaatkan }\end{array}$ & 3. $35,4 \%$ & $35,4 \%$ & \\
\hline & $\begin{array}{l}\text { 4. Titik akses dalam melakukan } \\
\text { penelusuran dokumen }\end{array}$ & 4. $67,7 \%$ & $67,7 \%$ & \\
\hline & $\begin{array}{l}\text { 5. Perlakukan terhadap } \\
\text { dokumen yang diperoleh }\end{array}$ & 5. $80,0 \%$ & $80,0 \%$ & \\
\hline & $\begin{array}{l}\text { 6. Bentuk dokumen yang } \\
\text { sering dimanfaatkan }\end{array}$ & $6.66,2 \%$ & $66,2 \%$ & $70,4 \%$ \\
\hline B. Kepuasan & 7. Kualitas koleksi repository & 7. $93,8 \%$ & $87,75 \%$ & \\
\hline Pemustaka & & $8.81,5 \%$ & & \\
\hline & 8. Kuantitas koleksi repository & 9. $75,4 \%$ & $75,4 \%$ & \\
\hline & 9. Kemudahan akses & $\begin{array}{l}10.72,3 \% \\
11.81,5 \% \\
\end{array}$ & $76,9 \%$ & \\
\hline & 10. Kualitas software Eprints & 12. $76,9 \%$ & $76,9 \%$ & \\
\hline & 11. Kuantitas hardware komputer & $13.73,8 \%$ & $73,8 \%$ & \\
\hline & 12.Hasil pemanfaatan & $\begin{array}{l}14.90,8 \% \\
15.70,8 \%\end{array}$ & $80,8 \%$ & \\
\hline
\end{tabular}

Sumber: Data primer diolah September 2014 
Berdasarkan tabel 7 diketahui bahwa total nilai rata-rata dari pemanfaatan koleksi repository Perpustakaan Fakultas MIPA UGM menggunakan Eprints adalah $70,45 \%$, sehingga menurut sebagian besar $(70,45 \%)$ responden, pemanfaatan koleksi repository Perpustakaan Fakultas MIPA UGM menggunakan Eprints sudah termasuk kriteria baik. Persentase rata-rata tertinggi terletak pada variabel kepuasan pemustaka pada indikator kualitas koleksi repository yaitu sebesar $87,75 \%$ dan persentase ratarata terendah pada variabel pola pemanfaatan koleksi repository pada indikator jumlah dokumen yang dimanfaatkan yaitu sebesar $35,4 \%$.

\section{PENUTUP}

\section{a. Kesimpulan}

Berdasarkan analisis dan pembahasan yang diuraikan di atas, diperoleh kesimpulan bahwa:

1. Koleksi repository yang berhasil diunggah ke dalam softwareEprints oleh petugas perpustakaan selama 1 bulan (Juli 2014) adalah sebesar 3.100 dokumen (judul). Apabila dilihat dari segi jumlah sudah mencapai target semula yaitu sebesar 2.934 judul.

2. Pemanfaatan koleksi repository Perpustakaan Fakultas MIPA UGM menggunakan Eprints adalah sebesar $70,45 \%$, termasuk ke dalam kriteriabaik.

3. Prosentase rata-rata tertinggi terletak pada variabel kepuasan pemustaka terhadap pemanfaatan koleksi repository pada indikator kualitas koleksi repository yaitu sebesar $87,75 \%$ dan prosentase rata-rata terendah pada variabel pola pemanfaatan koleksi repository pada indikator jumlah dokumen yang dimanfaatkan per hari yaitu sebesar $35,4 \%$.

4. Persentase rata-rata tertinggi padavariabelpola pemanfaatan koleksi repositoy terletak pada indikator intensitaspemanfaatan dan perlakuan terhadap dokumen yang diperoleh yaitu sebesar $80,0 \%$ dan persentase rata-rata terendah pada indikator jumlah dokumen yang dimanfaatkan yaitu sebesar 35,4\%.

5. Persentase rata-rata tertinggi pada variabel kepuasan pemusaka terhadap pemanfaatan koleksi repository terletak pada indikator kualitas koleksi repository, yaitu sebesar $87,75 \%$ dan persentase rata-rata terendah pada indikator Kuantitas hardware komputer, yaitu sebesar $73,8 \%$.

\section{b. Saran}

1. Jumlah koleksi repository perlu segera ditambah dengan meng-upload koleksi repository, sehingga lebih banyak dokumen yang dimanfaatkan oleh mahasiswa, mengingat baru $30 \%$ koleksi yang di-up load. Hal ini berdasarkan pada hasil analisis bahwapersentase rata-rata terendah terletak pada variabel pola pemanfaatan koleksi repository pada indikator jumlah dokumen yang dimanfaatkan per hari yaitu baru sebesar $35,4 \%$.

2. Jumlah komputer perlu ditambah agar lebih banyak mahasiswa yang memanfaatkan koleksi repository dan tidak terjadi antrian. $\mathrm{Hal}$ ini berdasarkan hasil analisis bahwa persentase rata-rata terendah pada indikator kuantitas hardware komputerdalam variabel kepuasan pemusakaterhadap pemanfaatan koleksi repository, yaitu sebesar $73,8 \%$.

\section{DAFTAR PUSTAKA}

Ahwan, Muh Ahlis, 2012. Ketersediaan koleksi digital UNDIP Institutional Repository dalam memotivasi pemustaka menyusun tesis di Perpustakaan Program Studi Magister Linguistik Universitas Diponegoro. http://download.portalgaruda.org/article.php?a rticle $=74911$ \&val $=4723$. Diakses pada tanggal 14April 2014.

Arikunto, Suharsimi, 2002. Prosedur Penelitian: Suatu Pendekatan Praktik. Jakarta: Rineka Cipta.

Arikunto, Suharsimi,1993. Prosedur Penelitian: Suatu Pendekatan Praktik. Jakarta: Rineka Cipta.

Badudu, Jusuf Syarief, 1994. Kamus Umum bahasa Indonesia. Jakarta: Pustaka Sinar Harapan.

Fuad, Miftakhul Yazid, 2013. Evaluasi Kualitas Perangkat Lunak Eprints untuk Pengelolaan Perpustakaan Digital (Studi Kasus di Perpustakaan UIN Sunan Kalijaga Yogyakarta). Skripsi: Yogyakarta: Program Studi Ilmu Perpustakaan Fakultas Adab dan Ilmu Budaya Universitas Negeri Sunan Kalijaga Yogyakarta.

Hadi, Sutrisno, 1981. Metodologi Research. Yogyakarta: Yayasan Penerbitan Fakultas Ilmu Psikologi UGM. 
Hermawan S, Rachman dan Zen, Zulfikar, 2006. Etika Kepustakawanan: Suatu Pendekatan Terhadap Profesi dan Kode Etik Pustakawan Indonesia. Jakarta: Sagung Seto

Lasa Hs. 2005. Manajemen Perpustakaan, Yogyakarta: Gama Media.

Narendra, Alb. Pramukti, 2014. Perpustakaan Digital dan Repositori Institusi Universitas (Sharing Pengalaman di UNIKA Soegijapranata Semarang). Info Persadha: Media Informasi Perpustakaan Universitas Sanata Dharma. Vol. 12, No. 1, Februari.

Pandapotan H., Daniel, 2013. Perencanaan dan Pengembangan Institusional Repository: "Studi Kasus di Perpustakaan ITS Surabaya". Malang: Pusat Riset Digital Library.

Pendit, Putu Laxman, 2008. Perpustaaan digital dari $A$ sampai $Z$. Jakarta: Cita Karyakarsa Mandiri.

Perpustakaan Nasional Republik Indonesia, 2008. Undang-undang Republik Indonesia Nomor 43 Tahun 2007 tentang Perpustakaan. Jakarta: Perpustakaan Nasional RI.

Prasetyo, Bambang dan Jannah, Lina Miftahul, 2000. Metode Penelitian Kuantitatif: teori dan aplikasi. Jakarta: Raja Grafindo Persada.

Qolyubi, Syihabuddin dkk., 2003.Dasar-dasar Ilmu Perpustakaan dan Informasi. Yogyakarta:
Jurusan Ilmu Perpustakaan dan Informasi Fak. Adab UIN Sunan Kalijaga.

Ridwan dan Adkon, 2006. Rumus dan Data dalam Aplikasi Statistik. Bandung: Alfabeta.

Rohmiyati, Yuli, 2006. Tesis: Pemanfaatan Perpustakaan Daerah Oleh Masyarakat di Badan Perpustakaan Daerah Yogyakarta. Yogyakarta: Sekolah Pasca Sarjana.

Siagian, Harly Christy M., 2009. Skripsi: Penerapan manajemen pengetahuan dalam pengolahan grey literature dan koleksi repository pada perpusakaan Universitas Sumatera Utara. Medan: Departemen Studi Ilmu Perpustakaan \& Informasi Fakultas Sastra Universitas Sumatera Utara

Sugiyono, 2005. Statistika Untuk Penelitian. Bandung: Alfabeta.

Sugiyono, 1998. Metode Penelitian Administrasi. Bandung: Alfabeta

Sulistyo-Basuki, 1991. Pengantar Ilmu Perpustakaan. Jakarta: Gramedia Pustaka Utama.

Supardi, A., 1979. Statistik. Bandung: Fakultas Tarbiyah IAIN Sunan Gunung Jati.

Sutarno NS., 2005. Tanggung Jawab Perpustakaan dalam Mengembangkan Masyarakat Informasi. Jakarta: Panta Rei. 